\title{
Sins of Inquiry: How to Criticize Scientific Pursuits
}

\author{
Marina DiMarco (corresponding author) \\ University of Pittsburgh \\ 1101 Cathedral of Learning \\ 4200 Fifth Avenue \\ Pittsburgh, PA 15260 \\ marina.dimarco@pitt.edu \\ Kareem Khalifa \\ Department of Philosophy \\ Middlebury College \\ Middlebury, VT 05753
}

Department of History and Philosophy of Science

\section{kkhalifa@middlebury.edu}

\section{Acknowledgments:}

We are very grateful to Jamie Shaw, Jared Millson, two anonymous reviewers, and audiences at the Pursuitworthiness in Science Workshop and the Center for Values in Medicine, Science, and Technology at the University of Texas at Dallas for thoughtful discussions, comments, and engagement with previous versions of this argument, as well as to Phin Choukas, Anthony Duci, Jacynda Espenshade, Anna Kim, Scott LaRochelle, Sean Lovett, Maddie McKean, Nam Nguyen, Gwen Orme, Sebin Park, Nicholas Quizon, Rachel Rose, and Aubrianna Wilson for their feedback and research assistance as students in the Middlebury College Winter Term 2021 Philosophy of Science course.

\begin{abstract}
:
Criticism is a staple of the scientific enterprise and of the social epistemology of science. Philosophical discussions of criticism have traditionally focused on its roles in relation to objectivity, confirmation, and theory choice. However, attention to criticism and to criticizability should also inform our thinking about scientific pursuits: the allocation of resources with the aim of developing scientific tools and ideas. In this paper, we offer an account of scientific pursuitworthiness which takes criticizability as its starting point. We call this the apokritic model of pursuit. Its core ideas are that pursuits are practices governed by norms for asking and answering questions, and that criticism arises from the breach of these norms. We illustrate and advertise our approach using examples from institutional grant review, neuroscience, and sociology. We show that the apokritic model can unify several indices of criticizability, that it can account for the importance of criticizing pursuits in scientific practice, and that it can offer ameliorative advice to erstwhile pursuers.
\end{abstract}




\section{Introduction}

Criticism is a staple of the scientific enterprise. A theory may be criticized for failing to explain anomalies. A model may be criticized for its dubious assumptions. An inference may be criticized for its lack of cogency. An experiment may be criticized for its shoddy design. However, examples such as these are most at home when thinking about confirmation. The criticism of scientific pursuits - the allocation of resources with the aim of developing a scientific idea or tool—is far less explored.

In this paper, we take some initial steps toward filling this gap in the philosophical literature on pursuit. The core ideas are that pursuits are practices governed by norms for asking and answering questions, and that criticism arises from the breach of these norms. We proceed as follows. Section 2 highlights the practical importance of criticizing pursuits. Section 3 provides a novel account of pursuit that takes the criticizability of pursuits as its starting point. Sections 4 through 6 present different ways of criticizing pursuits that fall out of our account.

\section{Why Criticizing Pursuits Matters}

We begin by underscoring three areas in which the criticism of pursuits seems vital. First, criticizing pursuits plays an important role in coordinating inquiry and stewarding resources. Consider the operation of agencies that fund science, such as the National Science Foundation and the European Research Council (Elliott and McKaughan 2009, Kitcher 2011, Shaw 2018, 2021). In such contexts, the number of projects (i.e., pursuits) vastly outstrips the available funding. Criticism of these pursuits is often an important means of narrowing down the list of fundable projects. Indeed, one might conjecture that projects most deserving of funding should do a better job withstanding pursuit-based criticisms than rival proposals. As an illustration, the US National Institutes of Health (NIH) offers explicit guidance to grant reviewers about how to 
criticize potential pursuits with respect to their inclusion of sex as a biological variable (SABV). These include directions about how to evaluate the inclusion or exclusion of SABV as a strength or weakness of a particular proposal, and standards of justification for overriding such criticism (NIH 2015, NIH "Reviewer Guidance"). We return to this example in Section 4.

Second, criticizing pursuits is central to the ways that non-scientists - politicians, entrepreneurs, activists, and the broader society — can hold scientists accountable. For example, Douglas $(2003,2009)$ argues that scientists are responsible for considering the foreseeable consequences of their actions in virtue of their general responsibility as moral agents, and these responsibilities extend to pursuit. As such, scientists can be criticized for failing to discharge these responsibilities. Similarly, public criticism of industry science can hold private interests to account for the safety and efficacy of, for instance, pharmaceutical products or potential environmental harms (Grinbaum and Groves 2013, Cranor 2017). These criticisms may lead to the development of new norms for research practices, such as those governing human subjects research; they may also influence professional codes of conduct for specific fields (Kourany 2010). Further, such criticisms can hold scientists accountable to the needs of would-be users of science, and scientists can hold one another accountable to these aims as well (Harding 1986, Elliott and McKaughan 2014, Parker 2020). More broadly, by holding scientists accountable in their pursuits, criticism can change the way both scientists and non-scientists understand the roles and responsibilities of scientists in specific contexts (see, e.g., Brown 2020). In Section 5, we discuss an example in which scientists enter the public sphere to criticize other scientists for pursuing a research program that appears to be both epistemically and morally dubious: neuroscientific research that systematically explains cognitive, affective, and behavioral patterns in terms of "hard-wired" sex differences in brains (Fine 2012). Concerns about perpetuating 
pernicious stereotypes are compelling reasons for scientists to be accountable to the public and can be a vital basis for criticizing scientific pursuits.

Third, criticizing pursuits allows scientists to shape each other's research agendas. This might happen on a small scale, e.g., when an advisor counsels her graduate student to steer clear of a certain project. However, it may also happen on a larger scale. Some published articles exhort researchers in their field to reorient their pursuits by disambiguating various concepts, changing key research questions, drawing more tentative conclusions from their studies, being more perspicuous in their explanations and methodological choices, and more carefully documenting different interventions. For example, in recent work calling for a "postcolonial sociology," Julian Go (2016) criticizes mainstream sociology's tendency to abstract away social relations between the Global North and Global South. Go claims that these abstractions foreclose important avenues of research, and his alternative places greater emphasis on global interdependence. Thus, his call for a postcolonial sociology is partly motivated by his criticisms of sociologists' established ways of pursuing knowledge. We return to this example in Section 6.

\section{An Apokritic Model of Pursuit}

We have argued that criticizing pursuits has far-reaching practical consequences. At first blush, philosophers would seem to be well-positioned to furnish key stakeholders — such as the funding agencies, scientists, and non-scientists described above - with useful frameworks for objecting to pursuits gone wrong. Unfortunately, this has not been a primary focus in the philosophy of pursuit. Rather, the pursuit literature has primarily been concerned to carve out a context of pursuit from the interstices of the context of discovery and the context of justification (Laudan 1977), to show that the logics of pursuit are more permissive than those of justification (Whitt 1990, McKaughan 2008, DiMarco and Khalifa 2019), to articulate the relationship between 
pursuit and the division of scientific labor (Shaw 2017, 2021), and to demonstrate the ways in which justification for theory pursuit is still, broadly speaking, rational or epistemic (Whitt 1992, Šešelja et al. 2012, Šešelja and Straßer 2014, Nyrup 2015, Fleisher 2018). In this section, we will take the criticizability of pursuits as our starting point. The remaining sections then serve as a preliminary advertisement for this approach.

An intuitive way of thinking about criticism is deontically. On such a view, to criticize something is to show that it violates some norm. For instance, we can criticize a basketball player for taking more than three steps without dribbling because of the rules about traveling. However, not all norms are explicit rules. We can also criticize basketball players who do not pass to open teammates when double-teamed. This is nowhere in the basketball rulebook but is recognized as a (defeasible) norm.

Typically, norms are thought to come in three flavors: permissions, obligations, and prohibitions. ${ }^{1}$ For instance, in most situations in the US, one is permitted to choose the color of their wardrobe, obligated to wear a shirt and shoes in commercial establishments, and prohibited from walking in public without covering one's nether regions. Furthermore, there are tight connections here. Not being permitted to do $A$ is tantamount to being obligated not to do $A$ and prohibited from doing $A$. Criticism happens when one violates these norms. So construed, two kinds of criticisms suggest themselves. First, one may be criticized for failing to fulfill one's obligations. Second, one may be criticized for doing something prohibited.

\footnotetext{
${ }^{1}$ This classification is not exhaustive, as deontic logic also recognizes, e.g., supererogatory and omissible actions (see McNamara and Van De Putte 2021). Deontic logic recognizes obvious sources of overlap among these categories, as actions that are not forbidden are permitted, and so forth. It is worth distinguishing the category of permissions from obligations because it seems likely that many scientific pursuits are neither forbidden nor obligated, but merely permitted.
} 
From a deontic perspective, violating obligations and prohibitions to engage in scientific pursuits is the basis of criticizing pursuits. To that end, we shall ground our account in apokritic norms, i.e., norms governing the answering of questions. ${ }^{2}$ More precisely:

- Apokritic Obligation: If a question $Q$ about object of inquiry $x$ has feature $F$, then some scientists with capability $C$ should pursue question $Q$ about $x$.

- Apokritic Prohibition: If a question $Q$ an object of inquiry $x$ has bug $B$, then no scientists should pursue question $Q$ about $x .^{3}$

At this level of abstraction, there is not much to be said about the key terms in these norms. For instance, features are just those properties of a question that obligate suitably capable scientists to pursue them; bugs do the same with prohibitions. Sections 4 through 6 provide concrete but highly varied examples of features, bugs, and capabilities. For instance, features can be anything from promoting fruitful research programs to serving the public good; bugs frequently run contrary to these goals. The appropriate capabilities range from scientific credentials to the achievement of standpoints. Despite this diversity, we hope that the core elements of apokritic norms provide a unifying framework for thinking about pursuit. Figure 1 charts the structure of the apokritic model. We will discuss the details of this structure below.

\footnotetext{
${ }^{2}$ We learned of this term from Millson (2014). It comes from the Greek verb apokrino, which means 'to give an answer.' Millson also discusses "erotetic" norms, which govern the asking (rather than the answering) of questions. We hope to discuss their relevance to pursuit at a later time.

${ }^{3}$ These are paradigmatic kinds of apokritic obligations and prohibitions; not every norm of this sort must have precisely these parameters.
} 
Some scientists with capabilities $C$ should have pursued question $Q$ about $x$.

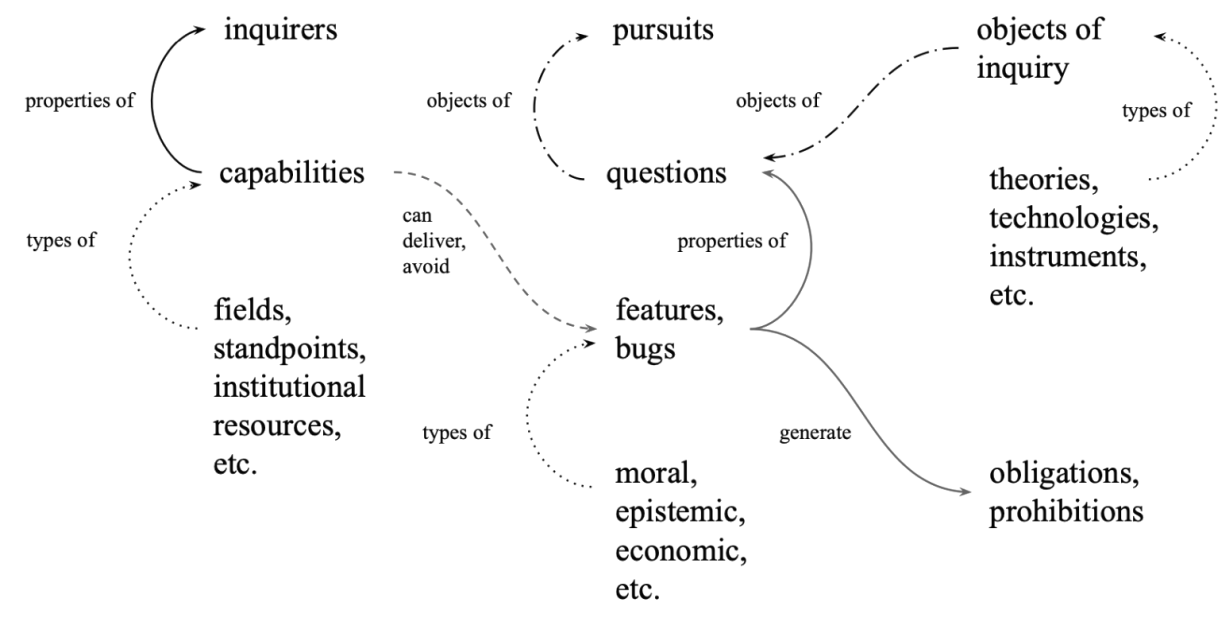

Figure 1. Relationships among features, bugs, and capabilities within the apokritic model.

Until we delve into these details, it will be useful to have some simple examples in front of us. (Though we hope these examples are plausible as described, they are meant to illuminate the contours of the model in particular contexts, rather than to exemplify a universal commitment to any particular apokritic norms.) As a simple example of an apokritic obligation, suppose that patients suffering from a newly discovered disease respond positively to antibiotics. Then some bacteriologists working on this disease ought to identify the strain of bacteria associated with this disease. Here, the object of inquiry is the disease; the features are the increased coherence of our microbiological knowledge and improved health outcomes to be gained by pursuing the question; the capabilities are specialization in bacteriology and some prior commitment to 
studying this disease; and the question is "Which strain of bacteria causes this disease?" In such a case, bacteriologists working on this disease may be criticized if none pursue this question. ${ }^{4}$

As a simple example of an apokritic prohibition, suppose that there is a study of a neural mechanism, but the experiments involved cause unnecessary suffering to some laboratory mice. The neural mechanism is the object of inquiry; the mice's unnecessary suffering is the bug; and "What happens to the neural mechanism when we put mice in such-and-such conditions?" is the question. In such a case, any scientist may be criticized for pursuing this question.

Below, we offer richer examples of aprokritic norms and their attendant criticisms. (Dare we call them "apokriticisms"?) For now, we want to highlight four general features of our account. First, our deontic approach to criticizing pursuits should not be confused with a deontological theory of ethics or rationality more broadly. Cast aside any associations of a Kantian categorical imperative, and feel free to reduce our talk of permissions, obligations, and prohibitions to your favorite normative theory, e.g., consequentialism. We remain silent on these issues. ${ }^{5}$ These disclaimers notwithstanding, we are optimistic about this way of articulating a basis for criticizing pursuits, as scientists are already familiar with deontic talk in the form of professional ethics and codes of conduct (see Kourany 2010, Brown 2013) and more broadly, in discussions of the moral responsibilities of scientists (e.g., Douglas 2009; 2014). In the spirit of Anderson (1993) and Brown (2020), we contend that a philosophical account of criticizing pursuits should be of some use to would-be critics and their respective targets. We submit that scientists' familiarity with deontic locutions contributes to our account's adequacy for this particular purpose à la Parker $(2009 ; 2020)$ and Jacquart (2016).

\footnotetext{
${ }^{4}$ Below, we further motivate the assumption that questions are the primary targets of pursuit.

${ }^{5}$ While deontic approaches are not the only resources available for theorizing pursuit, they lend themselves most naturally to the framework of criticism and to the provision of specific ameliorative advice. Thanks to Jamie Shaw, Rune Nyrup, and an anonymous reviewer for pushing us to clarify these points.
} 
Second, while canonical discussions take theories to be the objects of pursuit (Whitt 1990), more recent discussions have broadened this to include phenomena, correlations, and technologies, among other things (Šešelja, Kosolosky, and Straßer 2012). We prefer to think of questions as the chief targets of all pursuits. Questions, in turn, can be about different objects of inquiry, which include theories, phenomena, etc. This suggests the following:

An agent $S$ pursues a question $Q$ if and only if some of $S$ 's actions $A$ have the discovery of a correct answer to $Q$ as their goal. ${ }^{6}$

Making questions the targets of pursuit better represents scientists' research decisions at different stages and contexts of inquiry. In many pursuits, it is hard to see anything resembling a traditional theory in the research being criticized or the alternative offered in its stead. Consequently, the dominant philosophical preoccupation with theory pursuit will not be of much use in those cases. However, it is easy to recast these same pursuits in terms of questions, e.g., "Which concepts of recovery are useful for the treatment of the disease?" or "Which treatments lead to better recoveries?" For these and other questions, researchers of the disease must decide if allocating their research efforts is likely to result in an adequate answer.

Making questions the targets of pursuit greatly expands the reach of pursuit so that it permeates many stages of the research process. Thus, a focus on questions dislodges another common picture about pursuit as a distinct stage of research that happens after discovery but before justification. Such a conception of pursuit betrays an oversimplified and excessively linear model of inquiry (see Hicks 2014). In this way, the apokritic model's focus on questions simultaneously dispels this caricature of inquiry and expands the places that pursuit can make a difference. These strike us as welcome interventions in the philosophy of pursuit.

\footnotetext{
${ }^{6}$ See our (2019) “inquiry ticket” and Šešelja and colleagues' (2012) “unifying pattern" accounts of pursuit for similar ideas. Note that we previously used the word "person." We prefer the broader term "agent," so as to include collectives.
} 
Third, we are only seeking to characterize pro tanto criticisms of a pursuit. In other words, violating an apokritic norm may be justified all things considered. Returning to our earlier example, suppose that no bacteriologists pursue the question, "Which strain of bacteria causes the disease?" Under normal circumstances, this would warrant criticism. However, such criticisms can be overridden if bacteriologists have rediverted their research efforts to a far more urgent health crisis. (Imagine, if you can, that another disease is causing a global pandemic.) Although space prohibits discussion of how to weigh these competing considerations, we hope that our framework might inform such weighting procedures. In particular, we suggest (perhaps only as a regulative ideal) that if a pro tanto criticism is to be properly overridden, then someone should offer a legitimate response to that criticism. Like other accounts of transformative criticism (e.g. Longino 1990), we take it that the practical evaluation of criticism will be a contextual matter, and that the determination of such features as are contextually relevant to an all-things-considered evaluation of inquiry will be an iterative, pragmatic process (see e.g. Anderson 1993 and Brown 2020 for able guidance in this vein). ${ }^{7}$

Finally, our apokritic account of pursuit lends itself to contrastive criticisms of pursuits. The contrastive foci will be the different elements of our account: objects of inquiry, questions, and capabilities. For example:

- Object-Focused Criticism: Some scientists with capabilities $C$ should have pursued question $Q$ about $x$ (rather than another object of inquiry $x^{*}$.)

- Question-Focused Criticism: Some scientists with capabilities $C$ should have pursued question $Q$ (rather than some other question $Q^{*}$ ) about $x$.

\footnotetext{
${ }^{7}$ In this regard, it may be helpful to assimilate features and bugs into a functional account of values, such as the broadly Deweyan account offered by Brown (2020). On such an account, these weighing questions become generic problems of practical reason about how to reconcile incoherent or conflicting values and obligations in a particular context. Put this way, the point is not that there exists any special weighting algorithm(s) for all-things-considered evaluations of criticism, but rather, that criticism is the kind of thing which can be subject to these sorts of analyses.
} 
- Capability-Focused Criticism: Some scientists with capabilities $C$ (rather than some other capabilities $C^{*}$ ) should have pursued question $Q$ about $x$.

Finally, we can also make the quantifier of such statements a contrastive focus:

- Quantifier-Focused Criticism: Some (rather than no) scientists with capabilities $C$ should have pursued question $Q$ about $x$.

In paradigmatic cases, the truth of these contrastive statements will hinge on specific features and bugs. Moreover, additional kinds of contrastive criticisms are available on the apokritic model (see note 3). In certain cases, quantifier-based criticisms might use generalized quantifiers (most rather than few) or numbers ( $75 \%$ rather than 50\%). For instance, in the bacteriology example, it is not the case that all bacteriologists are obligated to pursue a question about this topic, but rather, that some (rather than no) bacteriologists should pursue such questions. Similarly, one might view capability-focused criticism as a species of the broader genus of resource-based criticism, where the contrastive focus might concern effort, money, equipment, etc. allocated to different pursuits, and where the targets of criticism might include funding institutions as well as researchers themselves. ${ }^{8}$ This would occasion contrastive criticisms such as "More (rather than the current amount of) funding should be allocated to pursue $Q$." In cases of finite resources, considerations of equity might be another source of quantifier-based criticism.

Contrastivism about pursuits is especially useful for our larger aim of providing tools for critically evaluating pursuits, since it allows us to pinpoint different loci of misguidedness with relative precision. Moreover, it is also useful in offering ameliorative advice: in all four cases, the way to correct the pursuit is to have some scientists with capabilities $C$ pursue question $Q$ about

\footnotetext{
${ }^{8}$ Our thanks to an anonymous reviewer for drawing this feature of the apokritic model to our attention.
} 
$x$. In this way, our framework promotes criticisms that are not only contrastive, but also constructive.

Let's illustrate some of these contrastive criticisms using our examples from above. As a baseline, let us suppose that some bacteriologists should have pursued the question, "Which strain of bacteria causes the disease?" where the object of inquiry is a disease $x$ that is deadly and highly contagious. However, instead they pursued the same question about another disease $x^{*}$ (rather than $x$ ) that has only mild symptoms and is not very contagious. In such a case, an object-focused criticism would be apt. To consider a question-based criticism, recall that our imaginary disease was mitigated by antibiotics. Suppose that in the face of this discovery, scientists pursued the question, "Which virus (rather than bacteria) causes the disease?" Since viral infections are not typically responsive to antibiotics, this question warrants criticism. Conversely, if virologists (rather than bacteriologists) pursued the question, "Which strain of bacteria causes the disease?" this would prompt a capability-focused criticism. Finally, if no (rather than some) bacteriologists pursued this question, this would prompt a quantifier-focused criticism.

With our apokritic model of pursuit in hand, we will now highlight some of its initial attractions. These are offered in the spirit of sketching suggestive lines of inquiry to be developed (or pursued?) in greater detail in future research.

\section{Features}

A question's features and bugs can take on many forms. Most notably, both features and bugs can be epistemic or moral in nature. ${ }^{9}$ We have already seen this with our toy examples. Because the disease is susceptible to antibiotics, an answer to the question of which bacteria cause the

\footnotetext{
${ }^{9}$ Despite using different terminology, our (2019) notion of an inquiry ticket anticipates the idea that features can be moral, as well as epistemic.
} 
disease is coherent with our microbiological knowledge, and this is a feature. The fact that pursuing a question about the neural mechanism requires causing unnecessary harm to laboratory mice is clearly a moral bug. We present some additional examples to highlight the variety of features and bugs that can inform apokritic norms.

In this section, we discuss epistemic and moral features. Section 5 does the same with bugs. That said, many other kinds of features and bugs exist. For instance, there are clearly economic features and bugs. Certain projects are too costly to pursue; others are too costly not to pursue. In cases of controversial scientific pursuits, political features and bugs may also inform apokritic norms. Introducing economic and political dimensions to apokritic norms also raises questions about how different kinds of features and bugs interact with each other. For instance, epistemic and moral features may outweigh economic and political bugs, or vice versa. These are the sorts of things that all things considered evaluations of pursuits must countenance. Given our more modest goals of providing an account of pro tanto criticism, we postpone discussion of these other kinds of features and bugs for another day.

At a general level, features are properties of a question that obligate scientists with certain capabilities to pursue that question. We will focus on those that have an "interesting-if-confirmed" structure, i.e., at least one answer to the question, upon being confirmed, would promote some good. Epistemic features arise when the good that would be promoted is epistemic; moral features, when the good is moral.

The interesting-if-confirmed structure highlights several key elements of pursuit. First, it underscores a subjunctive dimension of features - they often foretell of benefits that an answer would possess if confirmed. ${ }^{10}$ Second, confirmation, rather than truth, frequently appears to be the lynchpin. Presumably, an answer already is true or false at the time of pursuit-what is

\footnotetext{
${ }^{10}$ In this regard, we owe much to Nyrup (2015) for clarifying this aspect of pursuit.
} 
lacking is evidence of its truth or falsity. Third, in comparison to earlier works in the epistemology of pursuit, our framework immediately suggests more specific kinds of pursuit: the specific questions to be pursued promise to deliver the good. However, this will concern several other questions about ways of confirming the answer. Furthermore, scientists' capabilities will concern proficiency in developing models and empirical tests to answer those questions. In this way, the apokritic model has the means to offer more targeted advice.

\subsection{Epistemic Features}

Recall that epistemic features are properties of questions that obligate suitably capable inquirers to pursue them. Arguably, much of the existing literature on pursuit (Laudan 1977, Nyrup 2015, Šešelja and Straßer 2014, Šešelja, Kosolosky, and Straßer 2012, Shaw 2018, Whitt 1990; 1992) has focused on identifying epistemic features under different banners. ${ }^{11}$ Call these authors "the epistemologists of pursuit." In this section, we argue that the apokritic model can extend the ideas found in the epistemology of pursuit into areas of science to which they previously did not apply.

To see how this works, consider the following apokritic obligation:

If an answer to a question about a theory would, upon being confirmed, increase the coherence of the current corpus of scientific knowledge, then some scientists with capabilities $C$ should pursue question $Q$ about that theory.

Consonant with our earlier reflections, we may think of coherence as an epistemic good promoted by the pursuit of a question about the theory. Give or take some nuances, the antecedent of this obligation is in the spirit of Šešelja and Straßer's (2014) concept of potential coherence, and to a lesser degree, Nyrup's (2015) recasting of inference to the best explanation as a rule of pursuit. However, we strongly suspect that the lessons offered with respect to coherence either include or can be extended to other epistemologies of pursuit.

${ }^{11}$ Fleisher's (2018) extrinsic epistemic or "inquisitive" reasons are also in the same family as epistemic features. 
The apokritic model fits naturally with these coherentist meditations. For instance, consider one of our contrastive criticisms from above:

Some (rather than no) bacteriologists should pursue the question, "What is the strain of bacteria that causes the disease?"

This rests on the following apokritic obligation:

If a disease is responsive to antibiotics, then some bacteriologists should pursue the question, "What is the strain of bacteria that causes the disease?"

Quite plausibly, a disease's responsiveness to antibiotics justifies the pursuit of questions about its bacterial causes because bacterial hypotheses cohere with the current corpus of medical knowledge about antibiotics, lending the promise of increased coherence to questions about these hypotheses. (This is a sense in which properties of objects of inquiry can inform features of questions.)

As we also noted, we aim to show how the apokritic model allows this coherentist account to be extended beyond theory pursuit. Consider for example:

If an instrument would, upon being properly calibrated, increase the coherence of the current corpus of scientific knowledge, then some scientists with capabilities $C$ should pursue question $Q$ about that instrument.

Here, the object of inquiry is not a theory, but an instrument. Yet the epistemic feature is still the question's potential to increase the coherence of a body of scientific knowledge. This highlights how scientists may only be concerned with enhancing the coherence of a narrower body of information than our first apokritic obligation suggested. Moreover, an obvious question would be, "How can the instrument be properly calibrated?" Indeed, pursuit of these more focused questions bears closer resemblance to the way that scientific inquiry is actually conducted. Scientists pursue theories by chasing down answers to rather specific research questions. Thus, we can see how the apokritic model's 
emphasis on questions provides another avenue for expanding and refining the epistemology of pursuit, so that it may give more specific guidance to erstwhile pursuers.

\subsection{Moral Features}

Moral features are properties of a question that obligate suitably capable scientists to pursue them in virtue of their moral value. Natural candidates for moral features are those features of scientific pursuits which contribute to the likelihood that a particular inquiry will lead to a morally valuable intervention. For instance, the potential to alleviate human suffering is a moral feature of inquiry in our disease example, as in the following apokritic obligation:

If a hypothesis would, upon being confirmed, facilitate the design of an intervention to improve health equity, then some scientists with capabilities $C$ should pursue question $Q$ about that hypothesis.

In this example, health equity is a moral good, and so the likelihood that pursuing the question can contribute to securing this good is a moral feature. Like epistemic features, one way to think of moral features is in terms of the moral benefits an answer to a question might have, if confirmed. Some scientific fields, such as social epidemiology, hold such interesting-if-confirmed moral features among their constitutive aims of inquiry (Krieger 2001, Keyes and Galea 2015, Valles 2018, Kaplan and Valles 2019).

\subsection{Features and Funding Decisions}

Recall that one important target of such guidance is with regard to the role of criticism in coordinating scientific inquiry. To see how epistemic and moral features inform these sorts of criticisms, let's revisit the case of the NIH sex as a biological variable (SABV) advice to reviewers. According to the NIH policy on sex as a biological variable, the inclusion of SABV is an epistemic feature of many possible pursuits: the agency promises that SABV will promote 
more generalizable and rigorous findings (NIH 2015, NIH Center for Scientific Review). Furthermore, this epistemic feature is supposed to be conducive to a moral feature: the NIH claims that these findings will promote better health. To this end, NIH provides grant reviewers with specific guidelines for criticizing proposals with regard to SABV: proposals should detail how they plan to disaggregate data by sex or provide strong evidence from the scientific literature explaining why they do not include SABV ("Reviewer Guidance”).

On the apokritic model, NIH reviewer criticism assumes something like the following: in many NIH proposals, including SABV holds the promise of increasing the coherence of our current biomedical knowledge. As such, the grant applicant ought to pursue a question about it. The objects of inquiry here are very heterogeneous, so this reads naturally as a source of question-based criticisms: for any object of inquiry concerning humans or other vertebrate animals, some scientists with the relevant capabilities should pursue a question about sex differences (e.g., disaggregate their data by sex). Importantly, as Ritz (2017) and Richardson (forthcoming) argue, these capabilities should include knowledge of whether and how best to operationalize SABV in a particular research context. Furthermore, the defeasible nature of this apokritic obligation in the NIH reviewer guidance accords with the pro tanto nature of our apokriticisms: grant proposals that exclude SABV should anticipate and respond to potential criticisms.

Of course, this is only one possible source of criticism in the NIH grant review process; we might also expect to find various capability-based criticisms, epistemic bugs, and so forth. Furthermore, the status of SABV in relation to both moral and an epistemic features is rightly contested (see Epstein 2007, Richardson et al. 2015, Gompers 2019, Pape 2021, Richardson forthcoming). Apokritic norms, like other norms, can themselves be the subject of criticism and 
revision. Our point is not to endorse $\mathrm{SABV}$, but rather to illustrate an explicit formulation of a role for criticism in stewarding the resources of the NIH, which are insufficient to pursue all possible projects. The SABV policy can be understood here as a source of apokritic obligation which can aid in coordinating inquiry.

The case of SABV exemplifies a general trend: namely, that epistemic and moral features are often entangled in practice. In fact, we should expect to find overlap between moral and epistemic features. Epistemic features may be relevant to our moral aims in the same way that Longino (1995) takes empirical adequacy, a canonical epistemic good, to be a feminist theoretical virtue insofar as it promotes feminist aims of inquiry, such as illuminating gender. Similarly, we might expect some moral features, such as characterizing our objects of inquiry in ways that accord with feminist or anti-racist values, to double as epistemic features insofar as they secure epistemic benefits (Anderson 2004). Moral and epistemic features may support one another, such that epistemic features provide justification for moral judgments and vice-versa (Anderson 2004; Brown 2020).

Indeed, as the example of NIH's use of SABV illustrates, epistemic and moral features often (though not always) obligate scientists to pursue one and the same question. Whereas much has been made about how non-epistemic values can fill the gap when epistemic values underdetermine the hypothesis to be accepted, there is a striking disanalogy in this example. The epistemic feature and the moral feature each provide a pro tanto reason to pursue certain questions about SABV. Thus, the epistemic and non-epistemic goods overdetermine the questions to be pursued. This is unsurprising in the context of stewarding resources for pursuits: with more projects than resources, identifying those projects that are resilient across a wider variety of pursuit-based criticisms would appear to be valuable information. Subsequent research 
would seek to identify the extent to which different kinds of features overdetermine apokritic obligations and to characterize contexts in which they offer conflicting advice about pursuit in funding decisions.

\subsection{Beyond "Interesting-If-Confirmed"}

Thus far, we have focused on epistemic and moral features that have the "interesting-if-confirmed" structure. In this structure, the prospects of a well-confirmed answer to a question promoting some epistemic or moral good triggers an obligation to pursue that question. However, features are not limited to the "interesting-if-confirmed" consequences of inquiry. Here we briefly sketch some other roles for features in apokritic obligations.

For instance, some features have an "interesting-if-pursued" structure, i.e., they have value independently of what could be confirmed about the answer to a question. As an example, consider another apokritic obligation:

If pursuing a question about a theory would promote warranted trusting relationships to the benefit of a community to whom science is accountable, then some scientists with capabilities $C$ should pursue $Q$.

In this case, pursuing the question is conducive to a moral good, warranted trusting relationships, independent of the answer to our question.

As another example, moral features might also include coherence with the ethical aims of inquiry, or facility with thick concepts, such as health. Characterizing an object of inquiry in a way that avoids reinforcing harmful stereotypes could be a moral feature in this sense. ${ }^{12}$ For example, Kourany $(2010,69-71)$ describes the work of Carolyn West, a psychologist who studies

\footnotetext{
${ }^{12}$ Obviously, avoiding harmful stereotypes could also be an interesting-if-confirmed moral feature, and is probably conducive to interesting-if-confirmed epistemic goods as well. But the moral good of avoiding stereotypes could, in principle, be independent of the answer to a question being pursued.
} 
domestic violence with the aim of highlighting similarities in patterns of domestic violence in Black and white communities. This line of inquiry has at least two moral features, on Kourany's account. First, it characterizes the object of inquiry in a way that avoids reinforcing stereotypes about violence in Black communities. Second, pursuing questions about domestic violence in this way makes it more likely that policy informed by this research will address the needs of Black survivors of domestic violence. Thus, moral features of the same question may be mutually supportive.

\section{Bugs}

While earlier work has focused on when something should be pursued, surprisingly little has been said about when something should not be pursued. In the apokritic model's jargon, this points to a neglect of bugs, i.e., those properties of questions that figure in apokritic prohibitions. As with features, we examine both their epistemic and moral varieties.

\subsection{Epistemic Bugs}

A suggestive but misguided idea is simply to think of epistemic bugs as the "evil twins" of the epistemic features alluded to above. On such a view, apokritic prohibitions are mere inversions of the apokritic obligations of the previous section, e.g.,

If the answer to question $Q$ about $x$ would, upon being well confirmed, decrease the coherence of the current corpus of scientific knowledge, then no scientists should pursue $Q$

The "evil twin proposal" even seems to have some initial plausibility. Consider our example of a question-focused criticism from above:

Some bacteriologists should have pursued the question, "Which strain of bacteria (rather than which virus) causes disease $x ? "$ 
Arguably, if an answer to the question, "Which strain of virus caused the disease?" could be well confirmed, then it would render much of our current biomedical knowledge incoherent. However, this hardly seems like a reason not to pursue it. Many claims that would, if confirmed, decrease the coherence of the current stock of scientific knowledge should be pursued. Such claims would pose probative challenges that scientists should countenance. Indeed, a question may raise epistemic problems that are nevertheless epistemic features. In many cases, these problems generate or highlight incoherence in the current state of scientific knowledge, and thus generate subsequent pursuits that seek to alleviate those problems by increasing the coherence of that body of knowledge in accordance with the apokritic obligations discussed here. ${ }^{13}$

The relevant apokritic prohibition-if disease $x$ is responsive to antibiotics, then no bacteriologists should pursue the question, "Which virus causes $x$ ?"- has the force that it does not because a well-confirmed answer to this question would decrease the coherence of biomedical knowledge. Rather, it is because the prospects of a well-confirmed answer to this question are bleak. However, even this is not enough to issue an apokritic prohibition. After all, a highly implausible answer to a question might still be more plausible than anything else available. So, it also matters that we have a clear alternative answer that has much better prospects of being confirmed - namely a bacterial explanation of the disease. Even when these conditions are met, we think that there is only a pro tanto prohibition to pursue questions that presuppose that there is such a cause. A question presupposes a proposition if every possible answer to the question entails the presupposition. Asking which virus caused an antibiotic-responsive disease presupposes that viruses cause antibiotic-responsive diseases. Since that assumption has a poor confirmatory track record, it functions as an epistemic bug.

\footnotetext{
${ }^{13}$ In many ways, Kuhn's account of puzzle-solving anticipates this idea.
} 
Thus, a suitable account of epistemic bugs must be far more discerning. We suggest the following:

If $a$ has a long track record of incoherence with the current state of scientific knowledge and an alternative to $a$ has a long track record of coherence with the current state of scientific knowledge, then no scientists should pursue questions that presuppose $a$. This apokritic prohibition is not simply the evil twin of the apokritic obligations discussed in Section 4.1. In such cases, there are (pro tanto) reasons for doubting that the question should be pursued in the first place. Unlike the simple inversion of apokritic obligations with which we started, this conception of epistemic bugs points to the real problem: presuppositions with track records of incoherence are highly unlikely to be justified in subsequent pursuits. ${ }^{14}$

\subsection{Moral Bugs}

Just as epistemic considerations can be either features or bugs, so too can moral considerations. Indeed, our earlier examples involving the unethical treatment of laboratory animals and problematic neuroscientific research into "hard-wired" sex differences in cognition both seem to be cases where scientists are engaged in criticizable pursuits because of moral bugs, such as cruelty and sexism.

Unlike epistemic bugs, moral bugs need not have a long track record and a clear alternative to generate apokritic prohibitions. Thus, the following apokritic prohibition can fund criticisms in many cases:

If pursuing question $Q$ about $x$ would cause significant moral harm, then no scientists should pursue $Q$.

Our examples of immoral pursuits seem to be instances of this prohibition, e.g.,

\footnotetext{
${ }^{14}$ In this sense, epistemic bugs have an obvious affinity with features of a degenerating research programme à la Lakatos (1970), though they are less exclusively theory-focused.
} 
If intervening on a neural mechanism would cause unnecessary harm to animals, then no scientists should pursue questions that involve this intervention.

One reason for this asymmetry between epistemic and moral bugs concerns the risks involved. If a pursuit only has epistemic bugs, incorrectly permitting it is likely to result in a loss of resources but little else and might even result in an unlikely discovery. Hence, the risk is minimal, and so a more detailed case involving track records and alternatives needs to be made for the prohibition. By contrast, if a pursuit has moral bugs, incorrectly permitting it is likely to result in moral harm. Insofar as these harms are sufficiently severe, the risks will be decisive, and so a more detailed case is not needed, since the pursuit will be bad irrespective of most track records and alternatives.

\subsection{Science (and Bugs) in the Public Sphere}

Both epistemic and moral bugs can help us to think about important dimensions of scientific accountability in the case of neurosexism. Let's begin with epistemic bugs. Defenders of using hard-wired sex differences in neuroscience often claim that sexual dimorphism in brain structure best explains observed sex differences in behavior or cognitive task performance (see e.g., Baron-Cohen 2003, Arnold 2004). However, their critics challenge the track records of such explanations.

The apokritic model can account for these criticisms in fruitful ways. Consider one especially clear methodological criticism of hard-wired research programs. ${ }^{15}$ Hard-wired research programs explain observed sex differences in behavior in terms of differences between "male" and "female" brains. However, a sizable body of neuroscientific research shows that

\footnotetext{
${ }^{15}$ The hard-wired approach is incoherent with other well-established findings: (1) scores obtained from groups of females and males substantially overlap on the majority of social, cognitive, and personality variables, (2) observed behavioral differences have multiple causes, ranging from genes to hormones to brain to behavior to social structure, and (3) these causes interact or are entangled in various ways. See Rippon et al. (2014) for a review.
} 
human brains demonstrate considerable variety for most traits, and this variability does not fall neatly along sexually dimorphic lines. Joel (2011) calls this phenomenon "mosaicism." This means that insofar as traits can be characterized as masculine or feminine, individual brains are a mixture of masculine and feminine traits.

Using the apokritic model, we can interpret this criticism as highlighting an epistemic bug: namely, incoherence. Mosaicism suggests that asking questions that presuppose essentially "male" and "female" brains is incoherent with much of our neuroscientific knowledge. That is, researchers ought not to ask questions that presuppose hard-wired sexual dimorphism, e.g. "Which hard-wired biological sex difference explains these observed patterns of behavior?"

The presupposition that hard-wired sex differences are explanatory is an epistemic bug: it has a long track record of such incoherence. Instead, neuroscientists ought to ask about similarities among brains, or perhaps about differences in some more specific candidate causal variable. That is, mosaicism motivates a question-based contrastive criticism. If the object of inquiry is observed differences in behavior, and mosaicism is part of our background theory in neuroscience, it is incoherent to ask a question about whether essentially dimorphic "male" and "female" brains explain the observed differences in behavior.

Criticisms of pursuits grounded in epistemic bugs continue a long tradition of feminist criticisms of sexist and androcentric research programs (e.g., Fausto-Sterling 1992, Longino and Doell 1983, Longino 1990; 2012, Lloyd 2005, Fine 2010, Jordan-Young 2010, Fine and Fidler 2015, Rippon 2019). Much like our discussion of mosaicism, these criticisms often take the form of pointing out straightforward methodological problems in sex differences research, such as lack of statistical power, small effect sizes, and reporting biases (Rippon et al. 2014, Fine and Fidler 2015, David et al. 2018). 
In such cases, neuroscientists use these and other methodological criticisms to hold one another accountable to shared standards of statistical inference, literature review, and so forth; what Douglas (2014) calls accountability to scientific reasoning. However, scientists' accountability, particularly to the broader society, is not exhausted by their appeal to epistemic features and bugs in criticizing each other's pursuits. For instance, critics also argue that hard-wired sex differences research reinforces and actively reproduces harmful gender stereotypes (Fine 2012), which is properly seen as a moral bug. This is a particularly interesting line of criticism because these harms are effected whether or not the hard-wired difference claims are true, meaning the moral bug can motivate the apokritic prohibition independently of the aforementioned epistemic bugs. As Fine $(2012,285)$ argues, "[t]he real effects of the products of scientists' research on our minds and society ... point to a need for scientists to consider the ethical implications of their work." The point is that neuroscientists should take into account the possible harms of their work, and Fine's criticism suggests that hard-wired research has failed to appropriately weigh the possibility of such harms in their pursuits. ${ }^{16}$ Fine's characterization of the moral bug here generates an apokritic prohibition which helps both scientists and non-scientists to hold hard-wired research programs to account for the broader consequences of their work. As Douglas $(2003,2014)$ points out, this is a perfectly legitimate basis for criticism because scientists should not be excused from considering the foreseeable consequences of their pursuits.

\footnotetext{
${ }^{16}$ While this example has obvious affinities with Douglas's (2009) articulation of the argument from inductive risk, the moral harms here are not obviously related to whether or not the hypotheses in question are true, since on Fine's account, they may be self-fulfilling false prophecies. So, this case is better cashed out on Douglas's more general account of responsibility in science. Thanks to Leela Cañuelas for pointing out this interesting feature of the example.
} 


\section{Capabilities}

Just as features and bugs are properties of questions, capabilities are properties of inquirers. The relationship between capabilities and apokritic obligations depends on the features and bugs of a particular question. Specifically, capabilities will be the kinds of resources, abilities, and expertise which are necessary, relevant, or valuable for capitalizing on features or for avoiding bugs in pursuit of a particular question. For instance, in order to pursue the question of which strain of bacteria is causing a disease in a way that delivers greater coherence of our scientific knowledge, a scientist may need to be capable of isolating the strain in question, performing a Gram stain, and preventing the strain in question from infecting other patients or contaminating other experiments throughout the course of inquiry. Similarly, properties of a question can point to the relevant capabilities by way of bugs: if no scientist is capable of performing an experiment without inflicting unnecessary suffering on mice, this would generate a generic apokritic prohibition, and if only some scientists are capable of doing so, then it would generate an apokritic prohibition for those who cannot.

Just as features and bugs are motley, so too are capabilities. Perhaps the most obvious of these capabilities concern scientists' areas of specialization or fields. However, we suggest that capabilities may also arise from standpoints, institutional resources, and other features of researchers and their social situations. Like our treatment of features and bugs, we survey these capabilities in the spirit of advertising the scope of our model and suggesting avenues for further inquiry. 


\subsection{Fields}

Because it is helpful to know who has the requisite capabilities best suited to answering the question of interest in a way that delivers features and avoids bugs, apokritic norms will frequently specify capabilities in terms of scientists' different professional qualifications, methodological repertoires, and areas of expertise. While there are several ways of characterizing these kinds of qualifications, we find it useful to think of them in terms of Darden and Maull's $(1977,44)$ classic account of a scientific field:

... a central problem, a domain consisting of items taken to be facts related to that problem, general explanatory factors and goals providing expectations as to how the problem is to be solved, techniques and methods, and, sometimes, but not always, concepts, laws and theories which are related to the problem and which attempt to realize the explanatory goals [... and often, ] a special vocabulary.

As we see it, fields are especially important in the shaping of research agendas. We illustrate this by highlighting the apokritic model's handshakes with three other literatures. First, the apokritic model can fruitfully contribute to philosophical accounts of disciplinary and interdisciplinary research. For instance, apokritic norms can figure in criticisms that inform boundary-policing between fields, e.g.,

Scientists in field $F$ (rather than scientists in field $F^{*}$ ) should have pursued question $Q$ about $x$.

Our example of Go's agenda-setting in sociology seeks to overcome such boundary policing. Thus, Go considers the following criticism raised by postcolonial theorist Seth (2009):

Postcolonial theorists (rather than historical sociologists) should pursue questions about Eurocentrism. 
Seth's criticism is rooted in the idea that sociology's field-specific method of discovering general theories that apply to all societies effaces cultural differences, and can thereby be weaponized to perpetuate Western imperialism. This criticism is indexed to features and bugs of questions about Eurocentrism. The criticism has merit if and only if there is a feature that postcolonial theorists are uniquely qualified to capitalize upon (perhaps the greater coherence that inquiry about interdependence between societies from the Global North and Global South might yield) or a bug to which historical sociologists are especially susceptible (allegedly, ethnocentric universalism). A common advertisement for interdisciplinary research in general argues that interdisciplinary collaborations are uniquely capable of delivering on features and avoiding such bugs in many contexts.

Second, the apokritic model also dovetails with accounts of the allocation of research efforts or cognitive division of labor (Kitcher 1990, Solomon 2001). In particular, an exciting research program would examine how different apokritic norms interact with the incentive structures and social mechanisms that are the current focus of this literature. Narrower, more specific apokritic obligations give scientists relatively targeted guidance about how to continue a research agenda, and who should do so. By contrast, broad apokritic obligations may lead to redundancy and inefficiency in the scientific pursuit of questions. In this sense, narrow apokritic obligations are conducive to an efficient division of cognitive labor. However, there is a clear danger in this: if the entire scientific community is subject to narrow apokritic obligations, certain questions are likely to fall through the cracks and not get pursued. Hence, an interesting project would examine how to balance the guidance that comes with narrower apokritic obligations with the greater coverage that comes with more sweeping apokritic obligations. 
As an example of these kinds of "missed questions," consider once again Go's call for a postcolonial sociology. While not sympathetic to Seth's aforementioned criticism of sociology, Go does take the postcolonial critique of sociology's "metrocentrism" to be legitimate. Metrocentrism consists of sociologists' tendencies to treat societies in the Global North as representative of societies in general, to misrepresent the Global South as homogeneous and backwards, to omit important social relations between the Global North and Global South from its models and theories, and to undertheorize colonialism's role in modernization and industrialization. Each of these indictments points to good sociological questions that are missing from the research agenda, e.g., "How do societies in the Global South differ from one another and from societies in the Global North?", "How do various societies in the Global North and Global South relate to one another?", and "How did colonialism influence industrialization?" As such, Go suggests that sociologists should look beyond their field, and borrow ideas from postcolonial theorists in the humanities.

Third, fields and apokritic norms come together in the literature on consensus and disagreement in science. As many have noted, consensus is epistemically laudable only under certain conditions (Miller 2013, Solomon 2001, Zollman 2010). The flipside of this is that scientific disagreements are frequently productive (De Cruz and De Smedt 2013, Fleisher 2019, Dang 2019). At least one mark of a healthy consensus is that various questions about an object of inquiry have been pursued by different fields, particularly when those fields recruit independent lines of evidence. Conversely, disagreements between fields are productive when they spark an “evidential arms race", i.e., each field attempts to develop more probative lines of inquiry and evidence so as to advance the debate. This is one sense in which the apokritic model is consistent with a broadly pluralist approach to inquiry: since our paradigmatic apokritic obligations only 
have existential quantifiers (some scientists with capabilities), it is possible for other scientists with exactly the same capabilities to pursue different questions, and for a variety of obligations citing diverse capabilities to point to the same question. ${ }^{17}$

Finally, although fields play an important role in apokritic norms, it is useful for there to be apokritic norms that invoke "field-independent" capabilities, e.g.,

If a question $Q$ has bug $B$, then (some/only) scientists using reliable methods for avoiding $B$ should pursue question $Q$ about $x$.

The capability in this norm — using reliable methods that avoid the bug — is not keyed to a specific field. Such field-independent norms seem useful for fending off silo-thinking and conservatism within fields. Moreover, field-independent norms can foster interdisciplinary collaboration.

\subsection{Standpoints}

In addition to the obvious value of field-independent norms, there are many contexts in which we should expect that outsiders to a particular field, or outsiders to science itself, are likely to possess pursuit-relevant capabilities. Feminist standpoint theorists have articulated an important sense in which the ability to deliver on a feature or avoid a bug is socially situated in relation to power.

Standpoint theorists argue that the experiences of marginalized people, together with the resources they develop to understand these experiences, may confer an epistemic advantage, or allow marginalized knowers to access epistemic resources more readily than others (Harding 1986, Intemann 2010, Wylie and Sismondo 2015). Importantly, for contemporary standpoint theorists, this privileged epistemic access is not automatic, but rather reflects an achievement

\footnotetext{
${ }^{17}$ Note that the pro tanto nature of apokritic norms also lends itself to pluralism, as scientists subject to the same obligations or prohibitions may reach different all-things-considered judgments in different contexts.
} 
(Wylie 2012). These epistemic resources might include, for example, an understanding of the ways in which scientific pursuits are shaped by patriarchy, or an appreciation of the effects of a particular pursuit on the lives of women (Harding 2011, Fine 2012). Women of color's epistemic advantages often involve additional insights concerning racism, its intersections with patriarchy, and white women's complicity in reinforcing certain racialized power dynamics (Hill Collins 1986, Martinez 1996).

Feminist standpoint theory can account for some instances in which outsiders to a particular field may actually be in a better position to attain some relevant background knowledge than members or insiders, and thus possess unique capabilities for particular pursuits (Hill Collins 1986, Harding 1993; Mills 2007). For example, Hill Collins (1986) articulates a unique sense in which Black feminist scholars might contribute to sociology from their position as "outsiders within" the field: although they acquire field-specific capabilities in their training as sociologists, they may also retain critical perspectives distinct from the historically white male sociological worldview. Achieving a standpoint can afford a scientist unique epistemological access to systems of oppression: an important and field-independent capability. In this sense, standpoints fund very similar "capability-based" contrastive criticisms to those of fields:

Some scientists with standpoint $S$ (rather than scientists without) should pursue question $Q$ about $x$.

For instance, in calling for a postcolonial sociology, Go proposes a "subaltern standpoint," by which to address some of the aforementioned metrocentric shortcomings in sociological research: 
By a subaltern standpoint, I mean a social position of knowing akin to a feminist standpoint, just that it is not rooted primarily in gender but rather in geopolitics and global social hierarchy (Go 2016, 159).

Go's subaltern standpoints are rooted in indigenous sociology, or "Southern Theory", in which social theories are cultivated from intellectual traditions of the Global South (e.g., Connell 2007). He motivates the importance of this standpoint by its capacity to bring "to the fore global imperial relations and conventional social science's place within it" (Go 2016, 161). These differences between metrocentric and subaltern standpoints underlie Go's criticism that scientists with the relevant standpoint-related capability ought to pursue the aforementioned sociological questions.

Standpoint theory offers an important and often field-independent kind of capability. Importantly for our apokritical purposes, however, standpoints are also frequently cast as a position from which to criticize scientific pursuits (Rolin 2006, Intemann 2010). In the example above, Hill Collins offers the standpoint of the outsider within as an epistemic resource to both the study of sociological phenomena and to sociology itself. Similarly, Intemann (2010) shows that standpoints offer a straightforward empirical resource for feminist social epistemology of science insofar as diverse standpoints can improve the critical machinery of scientific inquiry as developed by feminist empiricists (Longino 1990, 2002). On the apokritic account, we can parse these arguments as claims about the role that standpoints play in allowing agents to recognize features and bugs of a particular pursuit.

\subsection{Institutions}

Capabilities are often indexed to more general access to resources relevant to inquiry. These institutional resources constitute a third important suite of capabilities. Institutional capabilities 
relevant to scientific pursuits might include, for example, access to libraries, equipment, streamlined research coordination processes, workers, relationships with community stakeholders, computing power, or facility with research organisms. Thus, institutional capabilities reflect a more generic sense in which capabilities are socially situated.

Institutional capabilities are particularly salient in the context of criticizing scientific pursuits to coordinate inquiry. For example, the NIH instructs grant reviewers to consider both general features of the scientific "environment" in which a proposal will be pursued (e.g., equipment) and unique features of an institutional context, such as scientific collaborators or subject populations, which might contribute to the success of a particular pursuit (NIH 2016). Similarly, Dietrich et al. (2020) point out that institutional capabilities such as commitments to specialization in particular research organisms, like the Jackson Laboratory's commitment to mice, often inform researchers' capability to pursue questions about one organism rather than another. A researcher's position within a particular scientific community such as the Drosophila or Arabidopsis research communities provides access to important strains and organisms (Leonelli 2007). Community membership or institutional affiliation might also provide access to important infrastructure such as knowledge, skills, and materials relevant to successfully caring for and manipulating organisms of interest (Ankeny and Leonelli 2011). Researchers with access to exclusive and costly scientific resources, such as CERN, may find their pursuits under more strict scrutiny. ${ }^{18}$ These sorts of institutional capabilities might generate something like the following apokritic norm:

Scientists with institutional support $I$ (rather than scientists without) should pursue question $Q$ about $x$.

\footnotetext{
${ }^{18}$ Our thanks to an anonymous reviewer for suggesting this example.
} 
This is a sense in which institutional capabilities might sometimes overlap with field-related capabilities. We might also expect institutional capabilities to share substantial overlap with economic features and bugs. ${ }^{19}$

\section{Conclusion}

As we have shown, criticism of pursuits figures prominently in scientists' setting of research agendas, the allocation of research funds, and scientists' accountability to shared standards and to the broader public. We also hope to have shown how the criticism of pursuits can function as a fruitful springboard for theorizing about pursuits more broadly. Our core idea is that criticisms are frequently grounded in the violation of an obligation or prohibition. The remaining task was developing the kinds of obligations and prohibitions that figure in scientific pursuit—what we have called apokritic norms. Such norms are characterized by features, bugs, and capabilities.

As we have seen, each of these dimensions of an apokritic norm can assume myriad shapes and sizes. Both features and bugs can assume either an epistemic or moral valence. We have made some preliminary comparisons with the current literature on the epistemology of pursuit and on the role of non-epistemic values in pursuit, but more detailed comparisons are likely to yield further insights.

Moreover, we have suggested that other kinds of features and bugs, such as those of an economic or political valence, are possible. Future research would provide an exhaustive taxonomy of the different kinds of features and bugs and chart interactions among the resulting taxa. For instance, one might examine how democratic procedures commingle with different kinds of apokritic norms to produce novel accounts of well-ordered science (Kitcher 2011, Shaw 2018).

${ }^{19}$ For a treatment of pursuit closely resembling what we're calling economic features and bugs, see McKaughan (2008). 
With capabilities, we have discussed the role of fields, standpoints, and institutions, forging connections between pursuit and interdisciplinarity, the cognitive division of labor, consensus, disagreement, and feminist epistemology. As before, an exhaustive taxonomy of capabilities and a charting of the taxa's interactions is desirable. As this initial list already suggests, the apokritic model's conception of capabilities holds the promise of integrating discussions of pursuit with many topics in the social epistemology of science.

Finally, with its emphasis on criticism, the apokritic model should be placed in greater dialogue with those conceptions of science that also prize criticism (e.g., Longino 1990). A suggestive research project would compare and contrast the critical apparatus needed to vet pursuits versus those needed to vet other aspects of scientific practice, such as acceptance. Thus, criticizing scientific pursuits raises many questions that we hope will be pursued by capable inquirers.

\section{References}

Anderson, Elizabeth. 1993. Value in Ethics and Economics. Cambridge, Mass: Harvard University Press.

_ 2004 "Uses of Value Judgments in Science: A General Argument, with Lessons from a Case Study of Feminist Research on Divorce," 24.

Ankeny, Rachel A., and Sabina Leonelli. 2011. "What's so Special about Model Organisms?" Studies in History and Philosophy of Science Part A, Model-Based Representation in Scientific Practice, 42 (2): 313-23. https://doi.org/10.1016/j.shpsa.2010.11.039.

Arnold, Arthur P. 2004. "Sex Chromosomes and Brain Gender." Nature Reviews Neuroscience 5 (9): 701-8. https://doi.org/10.1038/nrn1494.

Baron-Cohen, Simon. 2003. The Essential Difference: Men, Women, and the Extreme Male Brain. London: Penguin. 
Brown, Matthew J. 2013. "The Source and Status of Values for Socially Responsible Science." Philosophical Studies 163 (1): 67-76.

https://doi.org/10.1007/s11098-012-0070-x.

. 2020. Science and Moral Imagination. Pittsburgh: University of Pittsburgh Press.

Connell, Raewyn. 2007. Southern Theory: The Global Dynamics of Knowledge in the Social Science. Cambridge: Allen \& Unwin.

Cranor, Carl F. 2017. Tragic Failures: How and Why We Are Harmed by Toxic Chemicals.

Oxford: Oxford University Press.

http://www.oxfordscholarship.com/view/10.1093/acprof:oso/9780190635756.001.0001/ acprof-9780190635756-chapter-5.

Dang, H. (2019). Do Collaborators in Science Need to Agree? Philosophy of Science, 86(5), 1029-1040. https://doi.org/10.1086/705444

Darden, Lindley, and Nancy Maull. 1977. "Interfield Theories.” Philosophy of Science 44

(1): 43-64. https://doi.org/10.1086/288723.

David, Sean P., Florian Naudet, Jennifer Laude, Joaquim Radua, Paolo Fusar-Poli, Isabella Chu, Marcia L. Stefanick, and John P. A. Ioannidis. 2018. "Potential Reporting Bias in Neuroimaging Studies of Sex Differences.” Scientific Reports 8 (1): 6082.

https://doi.org/10.1038/s41598-018-23976-1.

De Cruz, Helen, and Johan De Smedt. 2013. "The Value of Epistemic Disagreement in Scientific Practice. The Case of Homo Floresiensis." Studies in History and Philosophy of Science Part A 44 (2): 169-77. https://doi.org/10.1016/j.shpsa.2013.02.002.

Dietrich, Michael R., Rachel A. Ankeny, Nathan Crowe, Sara Green, and Sabina Leonelli. 2020. "How to Choose Your Research Organism." Studies in History and Philosophy of Science Part C: Studies in History and Philosophy of Biological and Biomedical Sciences 80 (April): 101227. https://doi.org/10.1016/j.shpsc.2019.101227.

DiMarco, Marina, and Kareem Khalifa. 2019. "Inquiry Tickets: Values, Pursuit, and Underdetermination.” Philosophy of Science 86 (5): 1016-28.

https://doi.org/10.1086/705446.

Douglas, Heather E. 2003. "The Moral Responsibilities of Scientists (Tensions between Autonomy and Responsibility)." American Philosophical Quarterly 40 (1): 59-68.

- 2009. Science, Policy, and the Value-Free Ideal. Pittsburgh: University of Pittsburgh Press.

—. 2014. “The Moral Terrain of Science.” Erkenntnis 79 (S5): 961-79.

https://doi.org/10.1007/s10670-013-9538-0. 
Elliott, Kevin C., and Daniel J. McKaughan. 2014. "Nonepistemic Values and the Multiple Goals of Science.” Philosophy of Science 81 (1): 1-21. https://doi.org/10.1086/674345.

Elliott, Kevin C., and Daniel J. McKaughan. 2009. "How Values in Scientific Discovery and Pursuit Alter Theory Appraisal.” Philosophy of Science 76 (5): 598-611. https://doi.org/10.1086/605807.

Epstein, Steven. 2007. Inclusion: The Politics of Difference in Medical Research. Chicago: University of 7hicago Press.

Fausto-Sterling, Anne. 1992. Myths of Gender: Biological Theories about Women and Men. 2nd ed. New York, NY: BasicBooks.

Fine, Cordelia. 2010. Delusions of Gender: The Real Science behind Sex Differences. London: Icon Books.

— 2012. "Explaining, or Sustaining, the Status Quo? The Potentially Self-Fulfilling Effects of 'Hardwired' Accounts of Sex Differences." Neuroethics 5 (3): 285-94. https://doi.org/10.1007/s12152-011-9118-4.

Fine, Cordelia, and Fiona Fidler. 2015. "Sex and Power: Why Sex/Gender Neuroscience Should Motivate Statistical Reform.” In Handbook of Neuroethics, edited by Jens Clausen and Neil Levy, 1447-62. Dordrecht: Springer Netherlands. https://doi.org/10.1007/978-94-007-4707-4 156.

Fleisher, Will. 2018. "Rational Endorsement.” Philosophical Studies 175 (10): 2649-75. https://doi.org/10.1007/s11098-017-0976-4.

_. 2019. "Method Coherence and Epistemic Circularity." Erkenntnis 84 (2): 455-80. https://doi.org/10.1007/s10670-017-9967-2.

Go, Julian. 2016. Postcolonial Thought and Social Theory. New York, NY: Oxford University Press.

Gompers, Annika. 2019. “Three Years In: 'Sex as a Biological Variable' Policy in Practice and an Invitation to Collaborate." GenderSci Lab (blog). December 10, 2019. https://www.genderscilab.org/blog/three-years-in-sex-as-a-biological-variable-policy-in -practice-and-an-invitation-to-collaborate.

Grinbaum, A., and C. Groves. 2013. "What Is 'Responsible' about Responsible Innovation? Understanding the Ethical Issues.” In Responsible Innovation, edited by R. Owens, J. Bessant, and M. Heintz, 119-42. Chichester, West Sussex, UK: Wiley.

Harding, Sandra. 1986. The Science Question in Feminism. Ithaca, NY: Cornell University Press. 
_ 1993. "Rethinking Standpoint Epistemology: 'What Is Strong Objectivity?'” In Feminist Epistemologies, edited by Linda Alcoff and Elizabeth Potter, 49-82. New York: Routledge.

- 2011. "Interrogating the Modernity vs. Tradition Contrast: Whose Science and Technology for Whose Social Progress?" In Feminist Epistemology and Philosophy of Science, edited by Heidi E. Grasswick, 85-108. Dordrecht: Springer Netherlands. https://doi.org/10.1007/978-1-4020-6835-5 5.

Hicks, Daniel J. 2014. “A New Direction for Science and Values." Synthese 191 (14):

3271-95. https://doi.org/10.1007/s11229-014-0447-9.

Hill Collins, Patricia. 1986. "Learning from the Outsider Within: The Sociological

Significance of Black Feminist Thought.” Social Problems 33 (6): 19.

Intemann, Kristen. 2010. "25 Years of Feminist Empiricism and Standpoint Theory: Where

Are We Now?" Hypatia 25 (4): 778-96.

https://doi.org/10.1111/j.1527-2001.2010.01138.x.

Jacquart, Melissa. 2016. "Similarity, Adequacy, and Purpose: Understanding the Success of Scientific Models." Ph.D. Thesis, London, Ontario: Western University. https://ir.lib.uwo.ca/etd/4129.

Joel, Daphna. 2011. "Male or Female? Brains Are Intersex." Frontiers in Integrative

Neuroscience 5. https://doi.org/10.3389/fnint.2011.00057.

Jordan-Young, Rebecca M. 2010. Brain Storm: The Flaws in the Science of Sex Differences. Cambridge, Mass: Harvard University Press.

Kaplan, Jonathan Michael, and Sean A. Valles. 2019. "Reflecting on What Philosophy of Epidemiology Is and Does, as the Field Comes into Its Own: Introduction to the Special Issue on Philosophy of Epidemiology." Synthese, May, s11229-019-02252-53.

https://doi.org/10.1007/s11229-019-02252-3.

Keyes, Katherine, and Sandro Galea. 2015. "What Matters Most: Quantifying an

Epidemiology of Consequence.” Annals of Epidemiology 25 (5): 305-11.

https://doi.org/10.1016/j.annepidem.2015.01.016.

Kitcher, Philip. 1990. "The Division of Cognitive Labor.” The Journal of Philosophy 87 (1): 5-22. https://doi.org/10.2307/2026796.

Society: The Philosophy of Philip Kitcher, edited by J. Gonzalez Wenceslao, 101:95-112. Poznan Studies in the Philosophy of the Sciences and the Humanities. Amsterdam: Rodopi. 
Kourany, Janet A. 2010. Philosophy of Science after Feminism. Studies in Feminist Philosophy. Oxford; New York: Oxford University Press.

Krieger, N. 2001. "A Glossary for Social Epidemiology.” Journal of Epidemiology \& Community Health 55 (10): 693-700. https://doi.org/10.1136/jech.55.10.693.

Lakatos, I. (1970). Falsification and the Methodology of Scientific Research Programmes. In A. Musgrave \& I. Lakatos (Eds.), Criticism and the Growth of Knowledge: Proceedings of the International Colloquium in the Philosophy of Science, London, 1965 (Vol. 4, pp. 91-196). Cambridge University Press. https://doi.org/10.1017/CBO9781139171434.009 Laudan, Larry. 1977. Progress and Its Problems: Towards a Theory of Scientific Growth. London: Routledge \& K. Paul.

Leonelli, Sabina. 2007. "Growing Weed, Producing Knowledge: An Epistemic History of Arabidopsis Thaliana." History and Philosophy of the Life Sciences 29 (2): 193-223. Lloyd, Elisabeth Anne. 2005. The Case of the Female Orgasm Bias in the Science of Evolution. Cambridge, MA: Harvard University Press.

Longino, Helen E., and Ruth Doell. 1983. "Body, Bias, and Behavior: A Comparative Analysis of Reasoning in Two Areas of Biological Science." Signs: Journal of Women in Culture and Society 9 (2): 206-27. https://doi.org/10.1086/494044.

Longino, Helen E. 1990. Science as Social Knowledge: Values and Objectivity in Scientific Inquiry. Princeton, NJ: Princeton University Press.

—. 1995. "Gender, Politics, and the Theoretical Virtues." Synthese 104 (3): 383-97. https://doi.org/10.1007/BF01064506.

- 2002. The Fate of Knowledge. Princeton, N.J: Princeton University Press.

- 2012. Studying Human Behavior. Chicago: University of Chicago Press. https://www.press.uchicago.edu/ucp/books/book/chicago/S/bo13025491.html.

Martínez, Theresa A. 1996. "Toward A Chicana Feminist Epistemological Standpoint: Theory at the Intersection of Race, Class, and Gender." Race, Gender \& Class 3 (3): $107-28$.

McKaughan, Daniel J. 2008. "From Ugly Duckling to Swan: C. S. Peirce, Abduction, and the Pursuit of Scientific Theories." Transactions of the Charles S. Peirce Society 44 (3): $446-68$.

McNamara, P., \& Van De Putte, F. (2021). “Deontic Logic.” In E. N. Zalta (Ed.), The Stanford Encyclopedia of Philosophy (Spring 2021). Metaphysics Research Lab, Stanford University. https://plato.stanford.edu/archives/spr2021/entries/logic-deontic/ 
Miller, Boaz. 2013. "When Is Consensus Knowledge Based? Distinguishing Shared Knowledge from Mere Agreement." Synthese 190 (7): 1293-1316. https://doi.org/10.1007/s11229-012-0225-5.

Mills, Charles W. 2007. "White Ignorance.” In Race and Epistemologies of Ignorance, edited by Shannon Sullivan and Nancy Tuana, 11-38. Albany: State University of New York Press.

Millson, Jared. 2014. "How to Ask a Question in the Space of Reasons.” Ph.D. Thesis, Atlanta, GA: Emory University.

National Institutes of Health. 2016. "Definitions of Criteria and Considerations for Research Project Grant (RPG/R01/R03/R15/R21/R34) Critiques.” NIH Grants \& Funding. March 21, 2016. https://grants.nih.gov/grants/peer/critiques/rpg.htm.

- Notice. 2015. "Consideration of Sex as a Biological Variable in NIH-Funded Research,” June 9, 2015. https://grants.nih.gov/grants/guide/notice-files/NOT-OD-15-102.html.

National Institutes of Heath. n.d. "Reviewer Guidance to Evaluate Sex as a Biological Variable (SABV).” NIH.

https://grants.nih.gov/grants/peer/guidelines general/sabv decision tree for reviewers. pdf.

NIH Center for Scientific Review. n.d. "Premise, Rigor, Sex as a Biological Variable.” NIH Center for Scientific Review. Accessed March 20, 2021. https://public.csr.nih.gov/FAQs/ReviewersFAQs/PremiseRigorSexBiologicalVariable. Nyrup, Rune. 2015. "How Explanatory Reasoning Justifies Pursuit: A Peircean View of IBE." Philosophy of Science 82 (5): 749-60. https://doi.org/10.1086/683262.

Pape, Madeleine. 2021. "Co-Production, Multiplied: Enactments of Sex as a Biological Variable in US Biomedicine.” Social Studies of Science 51 (3): 339-63. https://doi.org/10.1177/0306312720985939.

Parker, Wendy S. 2009. "Confirmation and Adequacy-for-Purpose in Climate Modelling." Proceedings of the Aristotelian Society, Supplementary Volumes 83: 233-49.

—. 2020. "Model Evaluation: An Adequacy-for-Purpose View." Philosophy of Science 87 (3): 457-77. https://doi.org/10.1086/708691.

Richardson, Sarah S. "Sex Contextualism." Forthcoming in Philosophy, Theory, and Practice in Biology.

Richardson, Sarah S., Meredith Reiches, Heather Shattuck-Heidorn, Michelle Lynne LaBonte, and Theresa Consoli. 2015. "Opinion: Focus on Preclinical Sex Differences 
Will Not Address Women's and Men's Health Disparities." Proceedings of the National Academy of Sciences 112 (44): 13419-20. https://doi.org/10.1073/pnas.1516958112.

Rippon, Gina. 2019. The Gendered Brain: The New Neuroscience That Shatters the Myth of the Female Brain. London: The Bodley Head.

Rippon, Gina, Rebecca Jordan-Young, Anelis Kaiser, and Cordelia Fine. 2014.

"Recommendations for Sex/Gender Neuroimaging Research: Key Principles and Implications for Research Design, Analysis, and Interpretation.” Frontiers in Human Neuroscience 8. https://doi.org/10.3389/fnhum.2014.00650.

Ritz, Stacey A. 2017. “Complexities of Addressing Sex in Cell Culture Research.” Signs:

Journal of Women in Culture and Society 42 (2): 307-27.

https://doi.org/10.1086/688181.

Rolin, Kristina. 2006. "The Bias Paradox in Feminist Standpoint Epistemology." Episteme:

A Journal of Social Epistemology 3 (1): 125-36. https://doi.org/10.1353/epi.0.0006.

Šešelja, Dunja, Laszlo Kosolosky, and Christian Straßer. 2012. “The Rationality of Scientific Reasoning in the Context of Pursuit: Drawing Appropriate Distinctions." Philosophica 86: 51-82.

Šešelja, Dunja, and Christian Straßer. 2014. "Epistemic Justification in the Context of Pursuit: A Coherentist Approach.” Synthese 191 (13): 3111-41.

https://doi.org/10.1007/s11229-014-0476-4.

Seth, Sanjay. 2009. "Historical Sociology and Postcolonial Theory: Two Strategies for Challenging Eurocentrism.” International Political Sociology 3 (3): 334-38.

https://doi.org/10.1111/j.1749-5687.2009.00079 4.x.

Shaw, Jamie. 2017. "Was Feyerabend an Anarchist? The Structure(s) of 'Anything Goes."” Studies in History and Philosophy of Science Part A 64: 11-21.

https://doi.org/10.1016/j.shpsa.2017.06.002.

_. 2018. "Why the Realism Debate Matters for Science Policy: The Case of the Human Brain Project.” Spontaneous Generations: A Journal for the History and Philosophy of Science 9 (1): 82-98. https://doi.org/10.4245/sponge.v9i1.27760. —. 2021. "Feyerabend's Well-Ordered Science: How an Anarchist Distributes Funds." Synthese 198 (1): 419-49. https://doi.org/10.1007/s11229-018-02026-3.

Solomon, Miriam. 2001. Social Empiricism. Cambridge, Massachusetts: MIT Press. https://books.google.com/books/about/Social Empiricism.html?id=SASNj9P7vgYC\&s ource $=\mathrm{kp}$ book description.

Valles, Sean A. 2018. Philosophy of Population Health Science: Philosophy for a New Public Health Era. Routledge. 
Whitt, Laurie Anne. 1990. "Theory Pursuit: Between Discovery and Acceptance." PSA: Proceedings of the Biennial Meeting of the Philosophy of Science Association 1990 (1): 467-83. https://doi.org/10.1086/psaprocbienmeetp.1990.1.192725.

—. 1992. "Indices of Theory Promise." Philosophy of Science 59 (4): 612-34. https://doi.org/10.1086/289698.

Wylie, Alison. 2012. "Feminist Philosophy of Science: Standpoint Matters." Proceedings and Addresses of the American Philosophical Association 86 (2): 47-76.

Wylie, Alison, and S. Sismondo. 2015. "Standpoint Theory, in Science." In International Encyclopedia of the Social and Behavioral Sciences, edited by James D. Wright, 2nd ed., 324-30. Elsevier.

Zollman, Kevin J. S. 2010. “The Epistemic Benefit of Transient Diversity.” Erkenntnis 72: 17-35. 